\title{
Impact of a positive family history on diagnosis, management, and survival of breast cancer: different effects across socio-economic groups
}

\author{
H. M. Verkooijen · E. Rapiti · G. Fioretta • \\ V. Vinh-Hung $\cdot$ J. Keller $\cdot$ S. Benhamou $\cdot$ \\ G. Vlastos · P. O. Chappuis · C. Bouchardy
}

Received: 6 May 2009/ Accepted: 3 August 2009/Published online: 22 August 2009

(C) Springer Science+Business Media B.V. 2009

\begin{abstract}
Background This study aims to investigate whether increased awareness of breast cancer, due to a positive family history $(\mathrm{FH})$, reduces diagnostic, therapeutic, and survival differences between women of low versus high socio-economic status (SES).

Methods All breast cancer patients registered between 1990 and 2005 at the population-based Geneva Cancer
\end{abstract}

H. M. Verkooijen · E. Rapiti · G. Fioretta · J. Keller ·

C. Bouchardy

Geneva Cancer Registry, Geneva University, Geneva,

Switzerland

e-mail: ephhmv@nus.edu.sg

H. M. Verkooijen

Department of Epidemiology and Public Health, National

University of Singapore, Singapore, Singapore

V. Vinh-Hung

Oncology Center, University Hospital Brussels, Brussels, Belgium

S. Benhamou

INSERM, U946, Fondation Jean Dausset, CEPH, Paris, France

S. Benhamou

CNRS FRE2939, Gustave-Roussy Institute, Villejuif, France

G. Vlastos

Senology and Surgical Gynecologic Oncology Unit, Department of Gynecology and Obstetrics, Geneva University Hospitals, Geneva, Switzerland

P. O. Chappuis

Division of Genetic Medicine, Geneva University Hospitals, Geneva, Switzerland

C. Bouchardy $(\square)$

55 Boulevard de la Cluse, 1205 Geneva, Switzerland

e-mail: christine.bouchardymagnin@imsp.unige.ch
Registry were included. With multivariate logistic and Cox regression analysis, we estimated the impact of SES and FH on method of detection, treatment, and mortality from breast cancer.

Results SES discrepancies in method of detection and suboptimal treatment, as seen among women without a FH, disappeared in the presence of a positive FH. SES differences in stage and survival remained regardless of the presence of a positive FH. Overall, positive FH was associated with better survival. This effect was the strongest in women of high SES (age-adjusted Hazard Ratio [HR ${ }_{\text {ageadj }}$ ] $0.54[0.3-1.0]$ ) but less pronounced in women of middle $(0.77[0.6-1.0])$, and absent in women of low SES (0.80 [0.5-1.2]).

Conclusion A positive FH of breast cancer may reduce SES differences in access to screening and optimal treatment. However, even with better access to early detection and optimal treatment, women of low SES have higher risks of death from their disease than those of high SES.

Keywords Breast cancer - Social disparities . Family history $\cdot$ Survival $\cdot$ Early detection

\section{Introduction}

A positive family history of breast or ovarian cancer is a risk factor for breast cancer [1,2]. Several studies have indicated that a positive family history may lead to better compliance with early detection strategies, including mammography screening [3-6]. This could be due to the fact that women with affected family members are more aware of the risk of the disease and its associated complications and, therefore, more motivated to participate in prevention and screening activities. There is also evidence 
that breast cancer patients with affected family members hold less incorrect beliefs regarding cancer treatment and, as a result, receive more adequate or more complete therapy $[7,8]$. Having experience with breast cancer treatment in family members may allow patients to make better informed decisions regarding treatment.

Socio-economic status (SES) is an important prognostic factor in breast cancer, as breast cancer patients of low SES have a significantly higher risk of death from their disease than women of high SES [9-12]. In a previous study, we showed that the excess mortality risk is partly attributable to impaired access to, and lower participation in mammography screening programs, unfavorable stage distribution at diagnosis, and suboptimal treatment [12].

It is, therefore, in women of low SES that presence of a family history could potentially have the largest effect in terms of better access to screening and optimal treatment. In this population-based study, we examined whether the impact of a positive family history on method of detection, stage at diagnosis, treatment, and survival was different across the different socio-economic groups in the Swiss canton of Geneva.

\section{Methods}

We used data from the Geneva cancer registry, which records all incident cancers occurring in the population of the Geneva canton ( $\sim 20,000$ inhabitants) since 1970. It collects information from various sources and is considered accurate, as it is attested by its very low percentage $(<2 \%)$ of cases recorded from death certificates only [13]. All hospitals, pathology laboratories, and private practitioners in the canton are requested to report all cancer cases. Trained tumor registrars systematically abstract data from medical and laboratory records. Physicians regularly receive inquiry forms to complete missing clinical and therapeutic data. Recorded data include socio-demographic information, method of diagnosis, type of confirmation, tumor characteristics coded according to the International Classification of Diseases for Oncology [14], stage of disease at diagnosis, hormone receptor status, and treatment during the first 6 months after diagnosis. The registry regularly assesses survival, taking as reference date the date of confirmation of diagnosis or the date of hospitalization (if it preceded the diagnosis and was related to the disease). In addition to passive follow-up (standard examination of death certificates and hospital records), active follow-up is performed yearly using the files of the Cantonal Population Office (office in charge of the registration of the resident population). Cause of death is taken from clinical files.
In 1999, the Geneva Cancer Registry has set up a Familial Breast Cancer Registry by including detailed family history of cancer for all women diagnosed with invasive breast cancer in the Geneva population [15]. Family history of cancer is abstracted from medical records and classified as positive if at least one-first- or seconddegree relative had been diagnosed with breast or ovarian cancer. We decided to classify family histories of only ovarian cancer as positive as well, because ovarian cancer in family members is increasingly being mentioned as a risk factor for breast cancer on lay websites and online breast cancer risk calculators [16-18].

All other family histories were classified as negative. For breast cancer patients diagnosed between 1990 and 1999, family history was collected retrospectively, using information from medical records from the public university hospitals and private physicians. For $90 \%$ of the breast cancer patients, information on family history was obtained, and the accuracy of this retrospectively retrieved information has been validated [19]. Since 1999, family histories of breast and ovarian cancer are collected prospectively for all breast cancer patients.

SES was based on the woman's last occupation or, for the unemployed, that of the spouse. The Geneva cancer registry systematically retrieves the patient's last occupation from the files of the Cantonal Population Office. We used the classification of vital statistics that includes 12 major groups subdivided into 40 sub-major groups and 130 minor groups [20]. Occupational subgroups were classified into SES indicators in 7 levels based on the Social Classes of the British Registrar General [21]. For the purpose of this study, we regrouped SES in 4 levels only: low (manual employees, skilled, and unskilled workers, including farmers), middle (nonmanual employees and administrative staff), high (professionals, executives, administrators, entrepreneurs), and unknown.

For staging, we used the pathological pTNM (tumor node metastasis) classification system or, when not available, the clinical cTNM classification [22]). Stage was classified into five groups: stage 0/I ( $\mathrm{T}$ in situ or $\mathrm{T} 1$ and $\mathrm{N} 0$ ), stage II (T0 or T1 and N1, T2, and N0 or N1, T3, and $\mathrm{N} 0$ ), stage III (T0 or T1 or T2 and $\mathrm{N} 2, \mathrm{~T} 3$, and $\mathrm{N} 1$ or $\mathrm{N} 2$, $\mathrm{T} 4$, and any $\mathrm{N}$, any $\mathrm{T}$ and $\mathrm{N} 3$ ), stage IV (M1), and unknown. Tumor differentiation (grade) was classified as well differentiated (grade 1), moderately differentiated (grade 2), and poorly differentiated (grade 3). Estrogen receptor status was taken from the pathology report and classified as positive when $\geq 10 \%$ of the cancer cells expressed estrogen receptors.

Method of tumor detection was extracted from medical records and categorized as surveillance of healthy individuals (i.e., mammography or ultrasound screening or periodic clinical examination of asymptomatic individuals), 
symptoms, breast self examination, and other. Loco-regional therapy was categorized as breast-conserving surgery followed by radiotherapy, mastectomy, and other (including no surgery or tumorectomy without radiotherapy). Use of chemotherapy and hormone therapy was categorized as yes versus no.

In the current study, we included resident women diagnosed with in situ or invasive breast cancer between 1990 and $2005(n=5593)$. Patients without information on SES $(n=1077)$, family history of breast or ovarian cancer $(n=386)$, or both $(n=184)$ were excluded, leaving us with a dataset of 3,946 breast cancer patients.

We evaluated socio-economic differences in demographics, tumor characteristics, diagnostic, and therapeutic variables for women of increased versus low familial risk with chi square testing. With logistic regression analysis, we estimated the effect of family history on (1) likelihood of having tumor detected by surveillance (i.e., mammography, ultrasound, or clinical examination of asymptomatic individuals), (2) likelihood to present with early (stage 0/I) disease at diagnosis, (3) likelihood to receive inadequate loco-regional treatment (i.e., no surgery or tumorectomy without radiotherapy) and (4) likelihood to receive chemotherapy, for each of the SES strata. In this analysis, we adjusted for age only, in order not to over adjust for family-history-related variables. Effect modification of the effect of family history on these four variables by SES was tested by adding interaction terms to the logistic regression models. With Kaplan-Meier analysis, we calculated breast cancer survival rates for women at high versus low familial risk and used Logrank testing to evaluate survival differences. We used univariate Cox proportional hazards analysis to identify differences in breast cancer mortality risk between women of increased versus low familial risk for the three SES subgroups. With multivariate analysis, we evaluated to which extent survival differences between women at low versus increased familial risk were attributable to differences in method of detection, stage at diagnosis, loco-regional, and systemic treatment. Data were analyzed with SPSS (version 17.0), and differences were considered significant at a two-sided $p<0.05$.

\section{Results}

Of the 3,946 patients included in this study, 1,132 (28.7\%) had a family history of breast cancer. On the whole, 649 (16\%) were of high, 2,463 (62\%) of middle, and $834(21 \%)$ of low SES. Prevalence of a positive family history differed across the three SES groups: $34 \%$ of high, $29 \%$ of middle, and $24 \%$ of low SES women had affected first- or seconddegree family members $(p<0.001)$.
For all SES groups, women with a family history of breast cancer were on average 2 years younger than those without a family history: 55.1 versus 57.1 years $(p=$ 0.035 ) for women of high SES, 56.7 versus 59.0 years $(p<0.001)$ for women of middle SES, and 60.4 versus 62.2 years $(p=0.103)$ for women of low SES.

Among women without a family history of breast cancer, there were strong socio-economic differences in method of detection (Table 1). Specifically, women of high SES were much more likely to have their tumor detected by surveillance than those of low SES (37 versus 23\%, respectively; $p<0.001)$. In the presence of a positive family history, these socio-economic discrepancies were no longer present $(p=0.50)$.

Socio-economic differences in stage distribution were not affected by the presence of a positive family history. Less women of low SES presented with early stage disease than those of high SES, regardless of their positive family history. Women of low SES were also slightly less likely to present with well-differentiated tumors, which was the case for both women with and without a family history. There were no socio-economic differences in estrogen receptor, neither for women with nor for those without a family history of breast cancer (Table 1).

Among women without a family history, a significantly larger proportion of high SES women had received breastconserving surgery than of low SES women (Table 2). In the presence of a family history, this difference was less pronounced and no longer significant. Similarly, among women without a family history, those of low SES received chemotherapy significantly less frequently than those of high SES. In the presence of a family history, socio-economic differences in use of chemotherapy disappeared. SES was not related to use of hormone therapy, neither for women with nor for those without a family history of breast cancer.

Overall, presence of a family history increased the likelihood of having tumors detected by surveillance (age-

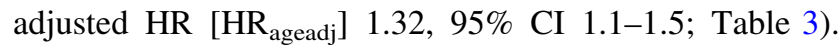
This effect was the strongest among women of low SES $\left(\mathrm{HR}_{\text {ageadj }} 1.60,95 \%\right.$ CI 1.1-2.3) and absent among women of high SES (HR $\mathrm{Hgadj}_{\text {age }} 1.07,95 \%$ CI $0.8-1.5$. There was no significant interaction between family history and SES in relation to method of tumor detection.

Family history of breast cancer did not increase the likelihood of being diagnosed with early stage disease, neither for all women $\left(\mathrm{HR}_{\text {ageadj }} 1.00\right.$ [0.9-1.2]) nor for the different socio-economic strata: $\mathrm{HR}_{\text {ageadj }} 1.08$ [0.8-1.5] for women of high SES, HR ageadj 0.95 [0.08-1.1] for women of middle SES and $\mathrm{HR}_{\text {ageadj }} 0.98$ [0.7-1.4] for women of low SES.

Women with a family history of breast cancer were significantly less likely to receive inadequate loco-regional 
Table 1 Patient and tumor characteristics of patients with versus without a family history of breast cancer by socio-economic status (SES)

\begin{tabular}{|c|c|c|c|c|c|c|}
\hline & \multicolumn{3}{|c|}{ Negative family history $(n=2,814)$} & \multicolumn{3}{|c|}{ Positive family history $(n=1,132)$} \\
\hline & $\begin{array}{l}\text { High SES } \\
(n=429)\end{array}$ & $\begin{array}{l}\text { Middle SES } \\
(n=1,748)\end{array}$ & $\begin{array}{l}\text { Low SES } \\
(n=637)\end{array}$ & $\begin{array}{l}\text { High SES } \\
(n=220)\end{array}$ & $\begin{array}{l}\text { Middle SES } \\
(n=715)\end{array}$ & $\begin{array}{l}\text { Low SES } \\
(n=197)\end{array}$ \\
\hline \multicolumn{7}{|c|}{ Method of detection } \\
\hline Surveillance $^{\mathrm{a}}$ & $157(37 \%)$ & $571(33 \%)$ & $148(23 \%)$ & $82(37 \%)$ & $272(38 \%)$ & $64(33 \%)$ \\
\hline Symptoms & $89(21 \%)$ & $403(23 \%)$ & $178(28 \%)$ & $32(15 \%)$ & $134(19 \%)$ & $37(19 \%)$ \\
\hline $\mathrm{BSE}^{\mathrm{b}}$ & $139(32 \%)$ & $523(30 \%)$ & $188(30 \%)$ & $80(36 \%)$ & $226(32 \%)$ & $73(37 \%)$ \\
\hline Other & $37(9 \%)$ & $235(13 \%)$ & $114(18 \%)$ & $24(11 \%)$ & $75(11 \%)$ & $23(12 \%)$ \\
\hline \multirow[t]{2}{*}{ Unknown } & $7(2 \%)$ & $16(1 \%)$ & $9(1 \%)$ & $2(1 \%)$ & $8(1 \%)$ & $0(0 \%)$ \\
\hline & \multicolumn{3}{|l|}{$p<0.001$} & \multicolumn{3}{|l|}{$p=0.501$} \\
\hline \multicolumn{7}{|l|}{ TNM stage } \\
\hline In situ/I & $208(49 \%)$ & $781(45 \%)$ & $230(36 \%)$ & $111(50 \%)$ & $312(44 \%)$ & $71(35 \%)$ \\
\hline II & $166(39 \%)$ & $693(40 \%)$ & $259(41 \%)$ & $89(41 \%)$ & $301(42 \%)$ & $88(45 \%)$ \\
\hline III/IV & $37(9 \%)$ & $223(13 \%)$ & $122(19 \%)$ & $19(9 \%)$ & $78(13 \%)$ & $33(17 \%)$ \\
\hline \multirow[t]{2}{*}{ Unknown } & $18(4 \%)$ & $51(3 \%)$ & $21(3 \%)$ & $1(0.5 \%)$ & $24(3 \%)$ & $5(3 \%)$ \\
\hline & \multicolumn{3}{|l|}{$p<0.000$} & \multicolumn{3}{|l|}{$p=0.008$} \\
\hline \multicolumn{7}{|l|}{ Differentiation } \\
\hline Good & $108(25 \%)$ & $478(27 \%)$ & $131(21 \%)$ & $54(25 \%)$ & $183(26 \%)$ & $42(21 \%)$ \\
\hline Moderate & $188(44 \%)$ & $686(39 \%)$ & $255(40 \%)$ & $94(43 \%)$ & $308(43 \%)$ & $82(42 \%)$ \\
\hline Poor & $80(19 \%)$ & $370(21 \%)$ & $149(23 \%)$ & $56(26 \%)$ & $161(23 \%)$ & $44(22 \%)$ \\
\hline \multirow[t]{2}{*}{ Unknown } & $53(12 \%)$ & $214(12 \%)$ & $102(16 \%)$ & $16(7 \%)$ & $63(9 \%)$ & $29(15 \%)$ \\
\hline & \multicolumn{3}{|l|}{$p=0.015$} & \multicolumn{3}{|l|}{$p=0.88$} \\
\hline \multicolumn{7}{|l|}{ ER status $^{\mathrm{c}}$} \\
\hline Negative & $47(11 \%)$ & $210(12 \%)$ & $76(12 \%)$ & $33(15 \%)$ & $82(12 \%)$ & $27(14 \%)$ \\
\hline Positive & $273(64 \%)$ & $1,061(61 \%)$ & $341(54 \%)$ & $144(66 \%)$ & $495(69 \%)$ & $126(64 \%)$ \\
\hline \multirow[t]{2}{*}{ Unknown } & $109(25 \%)$ & $477(27 \%)$ & $220(35 \%)$ & $43(20 \%)$ & $138(19 \%)$ & $44(22 \%)$ \\
\hline & \multicolumn{3}{|l|}{$p=0.439$} & \multicolumn{3}{|l|}{$p=0.277$} \\
\hline
\end{tabular}

${ }^{a}$ Including mammography, ultrasound or MRI screening, and periodic clinical breast examination

${ }^{\mathrm{b}}$ Breast self examination

${ }^{c}$ Estrogen receptor status

treatment (i.e., no surgery or tumorectomy without radiotherapy; $\mathrm{HR}_{\text {ageadj }} 0.68,95 \%$ CI $\left.0.5-0.9\right)$. This effect was similar among the different SES strata, and only significant for women of middle SES (Table 3). Overall, family history did not alter the likelihood of chemotherapy prescription. However, in the subgroup of women with low SES, those with a positive family history were significantly more likely to be treated with chemotherapy ( $\mathrm{HR}_{\text {ageadj }} 1.40$, $95 \%$ CI 1.0-2.1).

Overall, breast cancer patients with a positive family history had a lower risk of death from their disease than those without a family history (unadjusted $\mathrm{HR}$ [ $\left.\mathrm{HR}_{\mathrm{unadj}}\right]$ 0.69, 95\% CI 0.6-0.9; Table 4). After adjustment for age, method of detection, estrogen receptor status, grade, locoregional, and systemic therapy, a positive family history was still associated with a reduced breast cancer mortality risk ( $\mathrm{HR}_{\text {adj }} 0.81,95 \%$ CI 0.6-1.0).

Results by SES subgroup suggest that women of high SES had the highest mortality risk reduction associated with a positive family history $\left(\mathrm{HR}_{\mathrm{unadj}} 0.48,95 \%\right.$ CI $\left.0.3-0.9\right)$, while in women of low SES, a positive family history did not significantly affect mortality risk $\left(\mathrm{HR}_{\text {unadj }} 0.77,95 \% \mathrm{CI}\right.$ 0.5-1.2). After adjustment, there was still a trend toward lower mortality risk among women with a positive family history, in particular among women of high SES. However, the results were no longer significant.

\section{Discussion}

Women at increased perceived risk of breast cancer (often due to an increased familial risk) experience lower barriers to mammography screening and are, in the case of breast symptoms, more likely to seek timely consultation of specialists [5, 6, 23]. They hold less inaccurate beliefs toward cancer treatment, they feel more comfortable with treatment decisions and are more likely to receive adjuvant therapy $[6,7,23,24]$. 
Table 2 Treatment characteristics of patients with versus without a family history of breast cancer by socio-economic status

\begin{tabular}{|c|c|c|c|c|c|c|}
\hline & \multicolumn{3}{|c|}{ Negative family history $(n=2,814)$} & \multicolumn{3}{|c|}{ Positive family history $(n=1,132)$} \\
\hline & $\begin{array}{l}\text { High SES } \\
(n=429)\end{array}$ & $\begin{array}{l}\text { Middle SES } \\
(n=1,748)\end{array}$ & $\begin{array}{l}\text { Low SES } \\
(n=637)\end{array}$ & $\begin{array}{l}\text { High SES } \\
(n=220)\end{array}$ & $\begin{array}{l}\text { Middle SES } \\
(n=715)\end{array}$ & $\begin{array}{l}\text { Low SES } \\
(n=197)\end{array}$ \\
\hline \multicolumn{7}{|l|}{ Loco-regional therapy } \\
\hline $\mathrm{BCS}+\mathrm{RT}$ & $271(63 \%)$ & $1,073(61 \%)$ & $336(53 \%)$ & $150(72 \%)$ & $474(66 \%)$ & $133(68 \%)$ \\
\hline Mastectomy & $116(27 \%)$ & $448(26 \%)$ & $181(28 \%)$ & $54(25 \%)$ & $182(26 \%)$ & $45(23 \%)$ \\
\hline No surgery/BCS without RT & $40(9 \%)$ & $225(13 \%)$ & $117(18 \%)$ & $8(4 \%)$ & $58(8 \%)$ & $19(10 \%)$ \\
\hline \multirow[t]{2}{*}{ Unknown } & $2(0.5 \%)$ & $2(0.1 \%)$ & $3(0.5 \%)$ & $0(0 \%)$ & $1(0.1 \%)$ & $1(0.5 \%)$ \\
\hline & \multicolumn{3}{|l|}{$* p<0.001$} & \multicolumn{3}{|l|}{$* p=0.122$} \\
\hline \multicolumn{7}{|l|}{ Chemotherapy } \\
\hline Yes & $172(40 \%)$ & $680(39 \%)$ & $216(34 \%)$ & $89(41 \%)$ & $308(43 \%)$ & $85(43 \%)$ \\
\hline No & $242(56 \%)$ & $1,019(58 \%)$ & $409(64 \%)$ & $128(58 \%)$ & $390(55 \%)$ & $110(56 \%)$ \\
\hline \multirow[t]{2}{*}{ Unknown } & $15(4 \%)$ & $49(3 \%)$ & $12(2 \%)$ & $3(1 \%)$ & $17(2 \%)$ & $2(1 \%)$ \\
\hline & \multicolumn{3}{|l|}{$* p=0.029$} & \multicolumn{3}{|l|}{$* p=0.721$} \\
\hline \multicolumn{7}{|l|}{ Hormone therapy } \\
\hline Yes & $255(59 \%)$ & $1,093(63 \%)$ & $418(66 \%)$ & $147(67 \%)$ & $468(66 \%)$ & $132(67 \%)$ \\
\hline No & $125(29 \%)$ & $429(25 \%)$ & $125(20 \%)$ & $49(22 \%)$ & $180(25 \%)$ & $46(23 \%)$ \\
\hline \multirow[t]{2}{*}{ Unknown } & $49(11 \%)$ & $226(13 \%)$ & $94(15 \%)$ & $24(11 \%)$ & $67(9 \%)$ & $19(10 \%)$ \\
\hline & \multicolumn{3}{|l|}{$* p=0.004$} & \multicolumn{3}{|l|}{$* p=0.835$} \\
\hline
\end{tabular}

$B C S$ breast-conserving surgery, $R T$ radiotherapy

* p chi square of valid observations

Table 3 Impact of family history on probability of presenting with screen/surveillance detected tumors, early stage disease at diagnosis, receiving inadequate loco-regional treatment (no surgery, breast- conserving surgery without radiotherapy), and chemotherapy according to socio-economic status (SES)

\begin{tabular}{|c|c|c|c|c|c|c|c|c|c|}
\hline & \multirow[t]{2}{*}{$\begin{array}{l}\text { Family } \\
\text { history }\end{array}$} & \multicolumn{2}{|c|}{$\begin{array}{l}\text { Detection by screening } \\
\text { or clinical examination }\end{array}$} & \multicolumn{2}{|c|}{ Early stage $(0 / \mathrm{I})$ at diagnosis } & \multicolumn{2}{|c|}{$\begin{array}{l}\text { Inadequate loco-regional } \\
\text { treatment }\end{array}$} & \multicolumn{2}{|l|}{ Chemotherapy } \\
\hline & & $\begin{array}{l}\text { Unadjusted } \\
\text { OR }(95 \% \mathrm{CI})\end{array}$ & $\begin{array}{l}\text { Age-adjusted } \\
\text { OR }(95 \% \text { CI })\end{array}$ & $\begin{array}{l}\text { Unadjusted } \\
\text { OR }(95 \% \mathrm{CI})\end{array}$ & $\begin{array}{l}\text { Age-adjusted } \\
\text { OR }(95 \% \mathrm{CI})\end{array}$ & $\begin{array}{l}\text { Unadjusted } \\
\text { OR }(95 \% \mathrm{CI})\end{array}$ & $\begin{array}{l}\text { Age-adjusted } \\
\text { OR (95\% CI) }\end{array}$ & $\begin{array}{l}\text { Unadjusted } \\
\text { OR }(95 \% \mathrm{CI})\end{array}$ & $\begin{array}{l}\text { Age-adjusted } \\
\text { OR }(95 \% \text { CI })\end{array}$ \\
\hline \multicolumn{10}{|c|}{ All patients } \\
\hline & Negative & 1 (ref) & 1 (ref) & 1 (ref) & 1 (ref) & 1 (ref) & 1 (ref) & 1 (ref) & 1 (ref) \\
\hline & Positive & $1.30(1.1-1.5)$ & $1.32(1.1-1.5)$ & $1.01(0.9-1.2)$ & $1.00(0.9-1.2)$ & $0.53(0.4-0.7)$ & $0.68(0.5-0.9)$ & $1.21(1.1-1.4)$ & $1.01(0.9-1.2)$ \\
\hline \multicolumn{10}{|c|}{ Socio-economic status } \\
\hline \multirow[t]{2}{*}{ High } & Negative & 1 (ref) & 1 (ref) & 1 (ref) & 1 (ref) & 1 (ref) & 1 (ref) & 1 (ref) & 1 (ref) \\
\hline & Positive & $1.03(0.7-1.4)$ & $1.07(0.8-1.5)$ & $1.08(0.8-1.5)$ & $1.08(0.8-1.5)$ & $0.52(0.2-1.3)$ & $0.75(0.3-2.0)$ & $1.02(0.7-1.4)$ & $0.91(0.6-1.3)$ \\
\hline \multirow[t]{2}{*}{ Middle } & Negative & 1 (ref) & 1 (ref) & 1 (ref) & 1 (ref) & 1 (ref) & 1 (ref) & 1 (ref) & 1 (ref) \\
\hline & Positive & $1.27(1.1-1.5)$ & $1.30(1.1-1.6)$ & $0.96(0.8-1.1)$ & $0.95(0.8-1.1)$ & $0.50(0.3-0.7)$ & $0.63(0.4-1.0)$ & $1.19(1.0-1.4)$ & $1.04(0.9-1.3)$ \\
\hline \multirow[t]{2}{*}{ Low } & Negative & 1 (ref) & 1 (ref) & 1 (ref) & 1 (ref) & 1 (ref) & 1 (ref) & 1 (ref) & 1 (ref) \\
\hline & Positive & $1.59(1.1-2.3)$ & $1.60(1.1-2.3)$ & $1.00(0.7-1.4)$ & $0.98(0.7-1.4)$ & $0.68(0.4-1.2)$ & $0.79(0.4-1.4)$ & $1.48(1.1-2.3)$ & $1.40(1.0-2.1)$ \\
\hline \multicolumn{2}{|c|}{$\begin{array}{l}p \text { value } \\
\text { interaction } \\
\text { between SES } \\
\text { and FH }\end{array}$} & 0.29 & 0.29 & 0.27 & 0.81 & 0.64 & 0.82 & 0.28 & 0.21 \\
\hline
\end{tabular}

$O R$ odds ratio, $S E S$ socio-economic status, and $F H$ is family history

The current study confirms that a positive family history influences method of detection and treatment of breast cancer, especially in patients of low SES. In general, low
SES is associated with impaired access to screening and early detection, as well as suboptimal loco-regional and systemic treatment [12]. Our results show that women of 
Table 4 Impact of a positive family history on breast-cancer-specific mortality risk according to socio-economic status (SES)

\begin{tabular}{|c|c|c|c|}
\hline & $\begin{array}{l}\text { Unadjusted } \\
\text { HR }(95 \% \mathrm{CI})\end{array}$ & $\begin{array}{l}\text { Age-adjusted } \\
\text { HR }(95 \% \text { CI) }\end{array}$ & $\begin{array}{l}\text { Multi adjusted } \\
\text { HR }(95 \% \mathrm{CI})^{\mathrm{a}}\end{array}$ \\
\hline \multicolumn{4}{|l|}{ All patients } \\
\hline Negative family history & 1 (ref) & 1 (ref) & 1 (ref) \\
\hline Positive family history & $0.69(0.6-0.9)^{*}$ & $0.74(0.6-0.9)^{*}$ & $0.84(0.7-1.05)$ \\
\hline \multicolumn{4}{|l|}{ By socio-economic status } \\
\hline \multicolumn{4}{|l|}{ High SES } \\
\hline Negative family history & 1 (ref) & 1 (ref) & 1 (ref) \\
\hline Positive family history & $0.48(0.3-0.9)^{*}$ & $0.54(0.3-1.0)^{*}$ & $0.58(0.3-1.1)$ \\
\hline \multicolumn{4}{|l|}{ Middle SES } \\
\hline Negative family history & 1 (ref) & 1 (ref) & 1 (ref) \\
\hline Positive family history & $0.74(0.6-1.0)^{*}$ & $0.77(0.6-1.0)^{*}$ & $0.92(0.7-1.2)$ \\
\hline \multicolumn{4}{|l|}{ Low SES } \\
\hline Negative family history & 1 (ref) & 1 (ref) & 1 (ref) \\
\hline Positive family history & $0.77(0.5-1.2)$ & $0.80(0.5-1.2)$ & $0.85(0.5-1.3)$ \\
\hline $\begin{array}{l}p \text { value for interaction between } \\
\text { SES and family history }\end{array}$ & 0.45 & 0.47 & 0.36 \\
\hline
\end{tabular}

SES socio-economic status and $H R$ hazard ratio

$* p<0.01$

${ }^{a}$ Adjusted for age, stage, grade, estrogen receptor status, method of detection, loco-regional therapy, and chemotherapy

low SES were more likely to have their tumors detected by screening if they had affected family members. This effect was less pronounced in women of middle SES and absent in high SES women. Low SES women at increased familial risk were more likely to receive optimal loco-regional treatment and chemotherapy when compared to low SES women without a family history. In women of high and middle SES, these effects were, again, less pronounced.

Surprisingly, the increased probability of low SES patients to have their tumors detected by surveillance was not accompanied by an increased likelihood of being diagnosed with early stage disease. In addition, the different effect of family history on the proportion of screen detected cancers and more optimal treatment across SES strata did not translate into elimination of socio-economic differences in breast cancer mortality risk. On the contrary, only women of high and middle SES had a significant reduction in breast cancer mortality risk in the presence of a positive family history, whereas no significant association between family history and mortality risk was seen in women of low SES.

Previous studies on the impact of family history on survival after breast cancer have yielded ambiguous results, some indicating better, some similar, and some even worse survival rates for patients with a positive family history [25-27]. Differences in definition of family history, agerelated inclusion criteria, study design, definition of outcome measures (overall survival versus disease specific or disease free survival), and adjustment for confounders, as well as limited sample size of studied populations, make results of the various studies difficult to compare. In general, most population-based studies including women of all ages suggest a moderate protective effect of family history before adjustment for confounders. In our study, we also found a protective effect of a positive family history, which was no longer significant after adjustment for stage and diagnostic and treatment characteristics. This suggests that better access to early detection and optimal treatment among women with affected family members may partly explain the survival benefit associated with a positive family history.

Among women of low SES, the presence of a positive family history increased the probability of them being detected at an earlier stage and receiving adequate treatment. It is, therefore, surprising that the impact of a positive family history on breast cancer mortality was the lowest in this group. A possible explanation includes socioeconomic differences in life style. Unhealthy life style, in particular obesity and low levels of physical exercise, are increasingly being linked to adverse survival in breast cancer patients [28-30]. As low SES is associated with obesity, lower levels of physical exercise, and other unhealthy life style patterns [31, 32], the beneficial effect of improved access to screening and optimal treatment associated with a positive family history may be counteracted by the higher prevalence of unfavorable life style factors in breast cancer patients of low SES [33].

Another explanation could be that women of low SES may have been more often receiving nonstandard treatment regimens or suboptimal doses of chemotherapy. Griggs 
et al. [34] have shown that women with a low level of education are more than three times as likely to receive nonstandard chemotherapy regimens compared to women with a high level of education. In addition, obese and overweight breast cancer patients often receive intentionally reduced doses of chemotherapy, because of fear of excessive toxic effects [34]. Because the prevalence of obesity is higher among women of low SES [32, 33], these women could be at increased risk of suboptimal dosing. So even though in our study, women of low SES with a family history received significantly more often chemotherapy than those without affected family members, the survival benefit associated with adjuvant chemotherapy could have been reduced when optimal doses of chemotherapy have not been given. Unfortunately, we did not have information on type and dose of chemotherapy administered in our study.

A recent study from the Netherlands showed that women of high SES benefitted more from introduction of mass mammography screening, in terms of survival, than lower SES groups [35]. Even though survival rates of all SES groups improved significantly between 1983 and 1990 and 1997-2002 in the South of the Netherlands (where a population-based screening program was introduced in 1991), significantly higher increases in survival were seen in women of high SES (from 69 to 89\% 5-year cumulative survival) than in women of low SES (from 70 to $80 \%$ 5-year cumulative survival). The authors proposed that lower survival rates might be attributed to suboptimal treatment and poorer life style habits. As co-morbidity impairs relative survival of breast cancer [36], higher comorbidity rates among women of low SES could have increased their mortality risks as well. Because the Geneva Cancer Registry does not systematically register information on co-morbidity, we were not able to take the impact of this possible confounder into account.

We acknowledge that our study suffers from several limitations. Firstly, the limited sample size, especially in the subgroups of women with positive family histories and high or low SES, has led to less precise estimates in these subgroups and may explain lack of significance of some of our results. We used the patient's most recent occupation as registered at the Cantonal Population Office (the only measure of SES available for our study) to categorize patients into high, middle, and low SES groups. We acknowledge that, although it was collected at an individual level, occupation may not be sufficient to capture the multidimensional nature of SES, as it is also influenced by educational level, ethnicity, and many other factors. Inconsistent or inadequately measuring of socio-economic factors may affect conclusions about the relationship between SES and health outcomes. In addition, no information on SES was available for a large proportion of women (mainly housewives), which therefore had to be excluded from the study. However, in a previous study we found that breast cancer patients with unknown SES were rather comparable to those of middle SES in terms of tumor characteristics, diagnostic and treatment patterns, and breast cancer mortality risks [10]. To check whether this comparability was also true for this study, we performed a sensitivity analysis, regrouping the women with unknown SES with those of middle SES. This hardly affected the results, except for some small changes $(<6 \%)$ in some Hazard Ratios in Table 4.

Our definition of a positive family history was based on the presence of first- or second-degree relatives with breast or ovarian cancer $[1,2]$. Nevertheless, the presence of only ovarian cancer in family members may not have as strong an effect on awareness of the disease and preparedness for therapy as the presence of a breast cancer among family members. In our study, out of the 1,132 patients with a positive family history, $33(<3 \%)$ were classified as such based only on family members affected with ovarian cancer. Re-analysis of the data with exclusion of these 33 patients did not significantly alter any of the results. We recognize that there could be an association between SES and the level of patients' knowledge on their family history and accuracy of reporting. We were not able to check for this, but a previous validation study from our institute showed that in general, family history of breast cancer is reported rather accurately [17]. Finally, 10\% of our patient population had missing information on family history. This could have affected our results to a certain extent, if there was an association between actual presence or absence of a family history and the likelihood of it being accurately recorded.

Reasons for better breast-cancer-specific survival among women of high SES has never been completely elucidated. Indeed, better access to early detection and state of the art therapy are likely to explain part of the survival benefit of women of high SES (12). The results of the current study suggest that better awareness due to a positive family history may play a role as well. In this study, we have shown that women of high SES were more likely to have family members with breast or ovarian cancer. Our results also suggest a positive association between family history and outcome after breast cancer. If confirmed by others, the higher prevalence of positive family history among women of high SES could partly explain the mechanism behind the better survival after breast cancer in high SES women.

In conclusion, the presence of a positive family history eliminates SES differences in access to screening and optimal treatment. However, this does not translate into reduction in SES differences in breast cancer mortality risks. Even with better access to early detection and more optimal treatment, women of low SES still have higher risks of death from their disease than those of high SES. 
Acknowledgments The authors wish to thank Mrs. Stina Blagojevich for editorial support. This work was financially supported by the Swiss Cancer League (Grant number OCS-02070-04-2007).

\section{References}

1. Pharoah PD, Day NE, Duffy S, Easton DF, Ponder BA (1997) Family history and the risk of breast cancer: a systematic review and meta-analysis. Int J Cancer 71:800-809

2. Collaborative Group on Hormonal Factors in Breast Cancer (2001) Familial breast cancer: collaborative reanalysis of individual data from 52 epidemiological studies including 58,209 women with breast cancer and 101,986 women without the disease. Lancet 358:1389-1399

3. Figueiredo JC, Ennis M, Knight JA et al (2007) Influence of young age at diagnosis and family history of breast or ovarian cancer on breast cancer outcomes in a population-based cohort study. Breast Cancer Res Treat 105:69-80

4. Margolin S, Johansson H, Rutqvist LE, Lindblom A, Fornander T (2006) Family history, and impact on clinical presentation and prognosis, in a population-based breast cancer cohort from the Stockholm County. Fam Cancer 5:309-321

5. McCaul KD, Branstetter AD, Schroeder DM, Glasgow RE (1996) What is the relationship between breast cancer risk and mammography screening? A meta-analytic review. Health Psychol $15: 423-429$

6. Cohen M (2006) Breast cancer early detection, health beliefs, and cancer worries in randomly selected women with and without a family history of breast cancer. Psychooncology 15:873-883

7. Gansler T, Henley SJ, Stein K, Nehl EJ, Smigal C, Slaughter E (2005) Sociodemographic determinants of cancer treatment health literacy. Cancer 104:653-660

8. Verkooijen HM, Chappuis PO, Rapiti E et al (2006) Impact of familial risk factors on management and survival of early-onset breast cancer: a population-based study. Br J Cancer 94:231-238

9. Kaffashian F, Godward S, Davies T, Solomon L, McCann J, Duffy SW (2003) Socioeconomic effects on breast cancer survival: proportion attributable to stage and morphology. Br J Cancer 89:1693-1696

10. Karjalainen S, Pukkala E (1990) Social class as a prognostic factor in breast cancer survival. Cancer 66:819-826

11. Thomson CS, Hole DJ, Twelves CJ, Brewster DH, Black RJ (2001) Prognostic factors in women with breast cancer: distribution by socioeconomic status and effect on differences in survival. J Epidemiol Community Health 55:308-315

12. Bouchardy C, Verkooijen HM, Fioretta G (2006) Social class is an important and independent prognostic factor of breast cancer mortality. Int J Cancer 119:1145-1151

13. Bouchardy C (1997) Switzerland, Geneva. In: Parkin DM, Whelan SL, Ferlay J, Raymond L, Young J (eds) Cancer incidence in five continents, vol VII. International Agency for Research on Cancer, Lyon, pp 666-669

14. ICD-O International classification of diseases for oncology (1976) 1st edn. Geneva: World Health Organization

15. Bouchardy C, Verkooijen HM, Chappuis PO (2002) Occurrence and impact of genetic factors in breast cancer among the female population in Geneva: creation of the Geneva familial breast cancer registry. Bull Suisse Cancer 2650:165-168

16. http://www.nlm.nih.gov/medlineplus/breastcancer.html
17. http://www.cancerbackup.org.uk/Aboutcancer/Genetics/Cancer genetics/Breastovariancancer

18. http://www.nbocc.org.au/risk/familyfactors.html

19. Verkooijen HM, Fioretta G, Chappuis PO et al (2004) Set-up of a population-based familial breast cancer registry in Geneva, Switzerland: validation of first results. Ann Oncol 15:350-353

20. Mémento statistique de la Suisse (1998) Berne: Office Fédéral de la Statistique; 2000

21. Leete R, Fox AJ (1977) Registrar General's social classes: origins and uses. Popul Trends 8:1-7

22. TNM classification of malignant tumours, 6th edn. New York: 2002 UICC

23. Petrisek A, Campbell S, Laliberte L (2000) Family history of breast cancer. Impact on the disease experience. Cancer Pract 8:135-142

24. Tracy KA, Quillin JM, Wilson DB et al (2008) The impact of family history of breast cancer and cancer death on women's mammography practices and beliefs. Genet Med 10:621-625

25. Chappuis PO, Rosenblatt J, Foulkes WD (1999) The influence of familial and hereditary factors on the prognosis of breast cancer. Ann Oncol 10:1163-1170

26. Chang ET, Milne RL, Phillips KA et al. (2008) Family history of breast cancer and all-cause mortality after breast cancer diagnosis in the Breast Cancer Family Registry. Breast Cancer Res Treat (Epub ahead of print)

27. Russo A, Herd-Smith A, Gestri D et al (2002) Does family history influence survival in breast cancer cases? Int $\mathrm{J}$ Cancer 99:427-430

28. Dal ML, Zucchetto A, Talamini R et al (2008) Effect of obesity and other lifestyle factors on mortality in women with breast cancer. Int J Cancer 123:2188-2194

29. Holmes MD, Chen WY, Feskanich D, Kroenke CH, Colditz GA (2005) Physical activity and survival after breast cancer diagnosis. JAMA 293:2479-2486

30. Majed B, Moreau T, Senouci K et al (2008) Is obesity an independent prognosis factor in woman breast cancer? Breast Cancer Res Treat 111:329-342

31. Wang Y, Beydoun MA (2007) The obesity epidemic in the United States-gender, age, socioeconomic, racial/ethnic, and geographic characteristics: a systematic review and meta-regression analysis. Epidemiol Rev 29:6-28

32. Laaksonen M, Prattala R, Lahelma E (2003) Sociodemographic determinants of multiple unhealthy behaviours. Scand J Public Health 31:37-43

33. Clarke P, O’Malley PM, Johnston LD, Schulenberg JE (2008) Social disparities in BMI trajectories across adulthood by gender, race/ethnicity and lifetime socio-economic position: 1986-2004. Int $\mathrm{J}$ Epidemiol (Epub ahead of print)

34. Griggs JJ, Culakova E, Sorbero ME et al (2007) Effect of patient socioeconomic status and body mass index on the quality of breast cancer adjuvant chemotherapy. J Clin Oncol 25:277-284

35. Louwman WJ, van de Poll-Franse LV, Fracheboud J, Roukema JA, Coebergh JW (2007) Impact of a programme of mass mammography screening for breast cancer on socio-economic variation in survival: a population-based study. Breast Cancer Res Treat 105:369-375

36. Louwman WJ, Janssen-Heijnen ML, Houterman S et al (2005) Less extensive treatment and inferior prognosis for breast cancer patient with comorbidity: a population-based study. Eur J Cancer 41:779-785 